\title{
A review of multi-criteria decision-making methods for bioenergy systems
}

\author{
James A. Scott*, William Ho, and Prasanta K. Dey \\ Operations and Information Management Group \\ Aston Business School, Aston University \\ Birmingham B4 7ET, United Kingdom \\ *E-mail: scottja1@aston.ac.uk
}

\begin{abstract}
Bioenergy schemes are multi-faceted and complex by nature, with many available raw material supplies and technical options and a diverse set of stakeholders holding a raft of conflicting opinions. To develop and operate a successful scheme there are many requirements that should be considered and satisfied. This paper provides a review of those academic works attempting to deal with problems arising within the bioenergy sector using multi-criteria decision-making (MCDM) methods. These methods are particularly suitable to bioenergy given its multifaceted nature but could be equally relevant to other energy conversion technologies. Related articles appearing in the international journals from 2000 to 2010 are gathered and analysed so that the following two questions can be answered. (i) Which methods are the most popular? (ii) Which problems attract the most attention? The review finds that optimization methods are most popular with methods choosing between few alternatives being used in $44 \%$ of reviewed papers and methods choosing between many alternatives being used in $28 \%$. The most popular application area was to technology selection with $27 \%$ of reviewed papers followed by policy decisions with $18 \%$.
\end{abstract}

Keywords: Bioenergy; Multi-criteria; Multi-attribute; Decision making.

*Corresponding author 


\section{Introduction}

Bioenergy remains a fringe technology when compared with fossil fuel sources for many developed countries. However this situation could change rapidly with the continuation of attractive financial subsidies combined with market forces moving the interest of power suppliers and transport fuel producers towards the bioenergy resource. It is well recognised that the large scale expansion of biomass use for energy (heat, transport or power) can result in negative impacts upon the environment, society and the economy. The misuse of this resource creates many short and long-term problems which could outweigh the climate change benefits available from using these conversion technologies. Proper and sustainable management of bioenergy systems is therefore required.

The problems around managing, designing and implementing a bioenergy scheme are complex and multi-faceted. There are many stakeholders for each project and many requirements that must be satisfied for the successful long-term operation of a project. This multi-stakeholder, multi-requirement nature of problems regarding bioenergy [1] lends itself well to the application of multi-criteria methods. The intention of this paper is to systematically classify the existing literature using multi-criteria methods to address challenges in the bioenergy industry. To do so this review will address the following two questions: (i) Which methods are the most popular? (ii) Which problems attract the most attention? The answers to these questions will give an indication of current trends in research and the best direction for future research in order to further address the known barriers to bioenergy implementation. The bioenergy resource and related conversion technologies represent a major opportunity for the sustainable production of energy and is a route to meeting national carbon reduction targets. As governments continue to aim towards such targets decision making for bioenergy is likely to be a growing area of concern for governments, developers and utilities as well as the general public in the coming decades.

\subsection{Decision support systems and bioenergy}

Given the expected rise in the importance and rate of decisions being made in the bioenergy sector and the complexity of the systems being designed there is a clear application for decision making methods to be applied. Decision support systems (DSS) cover a wide and heterogeneous range of tools used for assisting decision makers. According to Alter (1980 p.71) [2] referenced by Power (2002 p.9) [3] a DSS can "take on many different forms and can be used in many different ways". The purpose of a decision support system is not to replace the decision maker but rather aid the decision making process by presenting complex and interlinked data in a way which allows the impacts of different choices to be more clearly understood. Decision support systems and multi-criteria decision making methods have been used to great effect in other energy industries to assist in decision making. The wind industry for instance has benefited greatly from the development of DSS software packages $[4,5]$ which cut down on development time and create a platform for understanding between different interested parties. Energy models in general are reviewed by [2] whilst Zhou et al [3] observe a growing proportional application of MCDM methods to the topics of electricity and renewable energy between 1975 and 2004.

Bioenergy project developers must interact with a wide reaching and complex system to bring a project to a stage where it is ready to construct. Decisions must be made regarding 
which technology should be used, which fuel sources should be contracted, how materials should be stored and transported, the capacity of the scheme and how the finances of the project are best managed and the choices made can impact on future decisions. For some of these decisions support systems already exist from other disciplines such as project finance or logistics. However other decisions are unique to the bioenergy industry. Many of the papers reviewed here offer some method which could be used to support the design of projects or decisions within the planning phase of bioenergy schemes, even if they are not explicitly described as DSS.

Previous reviews exist on decision making in renewable energy and biomass. Notably Baños et al. [6] presented a review of optimization methods that have been applied to sustainable energy. This review differs from that of Baños et al. [6] as it focuses on multi-criteria methods only and also on those applications regarding biomass and bioenergy. Wang et al. [7] presented a review paper of multi-criteria methods for renewable energy although in this case the review aimed to collect the different criteria which have been used by different authors, similarly to Baños et al. [6] the scope of the review is not focused on a particular technology. lakovou et al. [8] presented a review in the related area of energy from waste biomass which aimed to identify which barriers are being faced by that industry. This paper is different as the reviewed studies here cover a different scope and are focused on the methods to solve problems rather than the barriers being faced by industry.

This paper is organised as follows. Section 2 presents the procedure used to search for and identify the papers for review. Section 3 describes how the papers have been categorised and sections 3.1 through 3.5 give more detail on the reviewed articles. Section 4 discusses which methods have been used to address each problem and section 5 shows which problems attract the most attention. Section 6 describes other observations made on the reviewed literature including year of publication and national contexts studied. Section 7 gives recommendations for future research direction. Finally section 8 gives a conclusion to the paper.

\section{Research methodology}

ScienceDirect, Emerald and ProQuest databases were used to search for academic journal articles published between and including 2000 and 2010. Following a number of preliminary searches the broad key topics were identified for both methods used and areas of application. More detailed search strings were then formed for each database to identify all the relevant papers mentioning they key topics. Where possible only the fields of author keywords, abstract and title were searched. This reduced the overall number of results and excluded those papers only mentioning the key search terms in the references or literature review sections of papers.

For a paper to appear in this review it must apply a multi-criteria decision making technique and address a problem around bioenergy systems. Two groups of search terms were therefore used as shown in Table 1.

Table 1: Search terms

Search terms used for review

Search terms not used 


\begin{tabular}{|l|l|l|}
\hline Methods & $\begin{array}{l}\text { Multi-criteria, Multi-objective, multi- } \\
\text { attribute, MADM, MCDM }\end{array}$ & Decision making, Decision analysis \\
\hline Applications & $\begin{array}{l}\text { Biomass supply chain, biofuel, } \\
\text { biomass, bioenergy }\end{array}$ & $\begin{array}{l}\text { Renewable energy, waste, Energy } \\
\text { from waste }\end{array}$ \\
\hline
\end{tabular}

Using a combination of these search criteria a manageable selection of papers was identified. This involved not using the search terms "Renewable Energy", "waste", "energy from waste", nor the terms "Decision Making" or "Decision Analysis". These terms were not used as exclusions for the search but rather were not included in the search strings. This narrowed the review space considerably and placed a focus on those works directly related to the topic of this paper.

A total of 84 papers were identified using search strings from these keywords, the abstract and title of each was reviewed and 27 were found not to be relevant to the topic of interest, for instance papers about the development of bacteria growth mediums, ecosystems or those with a strong methodological emphasis. The reference lists of the remaining papers were checked to ensure that there were no other papers of relevance which had been missed by the search.

The remaining 57 papers were a heterogeneous set from authors around the world addressing differing problems under differing contexts. The abstracts and key findings or case studies of these papers were then analysed and notes were made on each paper. From the notes each paper was given a set of keywords which could be used to help with the classification of papers. Keywords were given to each paper describing the area(s) of application and the method being applied to make decisions. For the purposes of classification when a paper applied more than one method the method which provided the greatest contribution or was most relevant to the application being addressed or decision being made is used.

\section{Classification of papers}

From the notes created for each paper a categorisation of both methods and applications was created. A grouping of decision support system types from Turban et al. [9] was used to provide a basis for method categories with qualitative studies added to cover the wider range of papers identified by the review. A similar structure of methods is also shown in Zhou et al [3]. Table 2 shows the categories of methods applied.

Table 2: Categories of method used for categorisation

\begin{tabular}{|l|l|l|}
\hline Method & Sub Method & Description \\
\hline $\begin{array}{l}\text { Optimization } \\
\text { methods }\end{array}$ & $\begin{array}{l}\text { Optimization of problems } \\
\text { with few alternatives }\end{array}$ & $\begin{array}{l}\text { Finding the best solution from a small number } \\
\text { of alternatives }\end{array}$ \\
\cline { 2 - 3 } & $\begin{array}{l}\text { Optimization of problems } \\
\text { with many alternatives } \\
\text { using an algorithm }\end{array}$ & $\begin{array}{l}\text { Finding the optimal solution with problems with } \\
\text { many or infinite alternatives using a step-by- } \\
\text { step improvement. }\end{array}$ \\
\hline
\end{tabular}




\begin{tabular}{|l|l|}
\hline Predictive models & $\begin{array}{l}\text { Using some mathematical model to predict a } \\
\text { future situation including using simulation } \\
\text { techniques. }\end{array}$ \\
\hline Mainly qualitative study methods & $\begin{array}{l}\text { Collection and analysis of qualitative data from } \\
\text { interviews, surveys or focus groups }\end{array}$ \\
\hline Others & $\begin{array}{l}\text { Any methods used which do not easily fit into } \\
\text { the above categorization, including life-cycle } \\
\text { analysis and geographical information systems. }\end{array}$ \\
\hline
\end{tabular}

Multi-criteria decision making (MCDM) or multi-criteria decision analysis (MCDA) is a broad term used to describe any decision where multiple and conflicting criteria have influence on the decision. Criteria can take the form of attributes or objectives, attributes are the characteristics, qualities or measurements of performance whilst objectives are metrics which reflect the desires of the decision makers. A multi-objective method therefore aims to find a solution amongst alternatives that most satisfies these needs. A multi-attribute method however would identify the best alternative depending on the known attributes of those alternatives. These differences are subtle and the terms are interchangeable in most contexts. Overlap also exists in the literature with some studies using both attributes and objectives in the same model.

Within multi-criteria decision making optimization methods describe a broad family of methods which aim to select the best available option or action between some given set of potential actions. For the purposes of this paper these methods are divided into two subsections. Firstly methods that select between some short list of options and secondly methods which seek the overall maximum or minimum of a given objective function.

Section 3.1 divides the reviewed papers into groups depending upon the predominant method used. In some cases it appears that two methods have been used in the same study, for instance in Buchholz et al. [10] qualitative data is collected then converted to quantitative weightings. In these instances the method which is used to make the final decision or that which dominates the paper is used for categorization. There are also some papers which apply a method that could be classed as some hybrid between two method classifications. In these instances the method which is used to actually make the decision rather than some pre-processing of data is used for classification.

Table 3 shows the categories of applications used to compile the results of the review. The categories were selected to cover the majority of the papers identified in the search and also partly to correspond with the Political, Environmental, Social, Economic, Legal and Technological (PESTEL) framework. The topic of sustainability is important in the bioenergy field and is frequently studied in many disciplines beyond multi-criteria decision making. Sustainability has been given its own category for papers explicitly mentioning sustainability. Any papers which consider all three of the sustainability pillars of social sustainability, economic sustainability and environmental sustainability are also placed in the sustainability category. If a paper addresses two or less of these issues, they are placed accordingly and not in the sustainability category. Several papers address issues spanning more than one of 
the categories, in these cases they have been placed in all appropriate categories. Therefore a paper may belong to only a single method category, but many application categories.

Sections 3.1-3.5 show the reviewed papers with a brief description of the main points for each, the reviewed papers have been split by method as defined in Table 2 . 
Table 3: Categories of applications

\begin{tabular}{|c|c|c|}
\hline & Category & Description of application \\
\hline & $\begin{array}{l}\text { Political or legal } \\
\quad \text { issues }\end{array}$ & $\begin{array}{l}\text { Studies aiming to inform and advise government } \\
\text { policy on any issue regarding bioenergy }\end{array}$ \\
\hline & Technical issues & $\begin{array}{c}\text { Any studies looking to improve the process or } \\
\text { conversion efficiency of bioenergy conversion } \\
\text { technologies }\end{array}$ \\
\hline \multirow{3}{*}{ 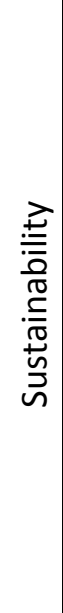 } & Economic Issues & $\begin{array}{c}\text { Any studies aimed at removing or solving the market } \\
\text { failures, economic problems or improving the cost } \\
\text { effectiveness of bioenergy systems through finance } \\
\text { models. }\end{array}$ \\
\hline & Environmental issues & $\begin{array}{l}\text { Studies addressing the issue of measuring and } \\
\text { reducing the environmental impact of bioenergy } \\
\text { systems. }\end{array}$ \\
\hline & Social Issues & $\begin{array}{l}\text { Studies which provide approaches or discuss } \\
\text { methods to minimize social impact or maximise social } \\
\text { benefit. This category also covers acceptance into } \\
\text { local communities and the creation of jobs. }\end{array}$ \\
\hline \multirow{5}{*}{ 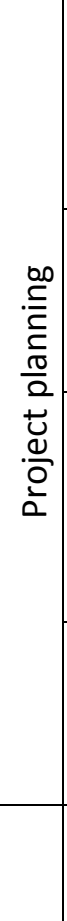 } & Operational & $\begin{array}{c}\text { Problems regarding the organisation and operation of } \\
\text { schemes either in the planning stage or on a day to } \\
\text { day basis. Problems regarding the movement of } \\
\text { materials and logistics. }\end{array}$ \\
\hline & Location & $\begin{array}{l}\text { Studies providing an approach to identifying the } \\
\text { preferable locations to build bioenergy facilities, can } \\
\text { be either supply or conversion locations. }\end{array}$ \\
\hline & Technology Selection & $\begin{array}{l}\text { Studies addressing the problem of selecting a } \\
\text { technology option for a bioenergy scheme at the } \\
\text { project planning stage. Usually this is for conversion } \\
\text { facility technology. }\end{array}$ \\
\hline & Capacity & $\begin{array}{l}\text { Studies addressing problems regarding the selection } \\
\text { of the optimal size and capacity for a scheme at the } \\
\text { project planning stage }\end{array}$ \\
\hline & Others & $\begin{array}{c}\text { A category produced to collect studies addressing } \\
\text { problems outside of the above. }\end{array}$ \\
\hline
\end{tabular}

\subsection{Optimization of problems with few alternatives}

A common group of methods from the optimization with finite options category is a family of outranking methods based on the principle of pairwise comparisons, probably the most 
well-known of these methods is the Analytical Hierarchy Process (AHP). The ELECTRE and PROMETHEE Methods also belong to this category.

PROMETHEE (Preference Ranking Organisation METhod for Enrichment Evaluations) is a multi-criteria decision aid methodology developed by Jean-Pierre Brans and Bertrand Mareschal since 1982. PROMETHEE is an outranking method based on the pairwise comparison of different options against the criteria defined by the decision maker. Geometric Analysis for Interactive Assistance (GAIA) is often then used to better visualise the outcomes of the decision process. PROMETHEE GAIA software has been developed to assist in the application of this method and is available for download [11].

ELimitation Et Choix Tradusant la REalité (ELECTRE - Elimination and Choice Expressing Reality) was introduced in the mid-1960's by SEMA consultancy employee Bernard Roy [12]. ELECTRE relies upon the weighted sum technique for making business decisions. The ELECTRE process involves two parts, firstly deciding the relationships between different actions or options, secondly a weighting of preference for each action is determined using a veto thresholds and importance coefficients approach [13].

Novel Approach to Imprecise Assessment and Decision Environments (NAIADE) is a multicriteria method which uses an evaluation matrix similar to those of the AHP, ELECTRE and PROMETHEE methods but can handle either crisp, stochastic or fuzzy measurements of the performance of each alternative against a given assessment criteria. NAIADE software has been developed to further facilitate the application of the method.

Beccali et al. [14] used a multi-criteria decision making methodology to make assessments of which low carbon energy sources should be pursued for the island of Sardinia. The ELECTRE III decision support system is used and is combined with a built-in fuzzy approach for dealing with linguistic values. This method is used to prioritise between 14 different options based on either an "economy-orientated" scenario, an "environmental-orientated" scenario or an "Energy saving and rationalization" scenario. The aim of the paper is to recommend a suitable renewable energy technology deployment strategy. The study recommends that the robustness of each solution could be assessed using a sensitivity analysis.

Afgan and Carvalho [15] compared various new and renewable technology options against a set of sustainability indicators. The result of the paper is a relative rating for each technology option with regards to sustainability. The study shows how the most sustainable choice will change when emphasis is placed on different sustainability criteria. The technologies compared are coal, solar thermal, geothermal, biomass, nuclear, solar photovoltaic (PV), wind, ocean, hydro and natural gas.

Haralambopoulos and Polatidis [16] mainly looked at geothermal power for the Greek Island of Chios although biomass is considered as an alternative energy source. This paper used the PROMETHEE II outranking method to evaluate four scenarios against a mixture of three quantitative and two qualitative criteria. These criteria were divided into different aspects or sub-criteria to assist with measurement of the quantitative parts of the problem. The paper aims to recommend the most suitable technology to best satisfy the criteria.

Khalil et al. [17] compared the PROMETHEE and GAIA methods. The aim of the study was to identify the optimal conditions for the treatment of sewage sludge. The study considered varying operating conditions such as reaction times, temperatures and oxidant dosage. The 
initial total solids and volatile solids amongst other factors were kept constant. The aim of the study was to better understand the optimal operating conditions to produce sludge with different qualities. One of the outputs of sewage sludge processing is biogas production and understanding these interactions can lead to the optimization of gas production.

Ulutaş [18] examined the forthcoming energy scarcity predicted for Turkey. The Analytical Network Process (ANP) method is applied to identify which technologies are most preferable for Turkey to satisfy national energy demand in to the future. The aim of the study was to make recommendations for policy makers when structuring future energy policy. The case study finds that biomass is the most preferable resource and technology for this context allowing a gradual replacement of traditional wood energy towards more modern biomass such as biodiesel and bioethanol.

Doukas et al. [19] applied the PROMETHEE II multi-criteria decision making (MCDM) method to select between policy interventions for Greece which intended to introduce greater renewable generation. The technologies considered included fuel cells, biomass gasification and co-firing, wind power, PV and the use of fossil fuels. Several possible future scenarios were then created based on future needs and requirements (Basic, Pessimistic, Optimistic and Unstable depending on various possible domestic and international factors). The criteria identified are categorised under the four dimensions of Economical, Technological, Environmental and Social. The overall conclusions of the Greek case study were that emphasis should be placed on indigenous resources such as lignite, wind and biomass.

Begic and Afgan [20] also used environmental, economic and social indicators for a multicriteria assessment, this time for the renovation of a thermal power facility in Bosnia \& Herzegovina. This study compared the rank of preference when using either a sustainability index to select the preferred technology or using an investment biased selection criteria.

Zhou et al. [21] presented a method to select between several fuel types including bioethanol and blends using biofuels. The multi-criteria analysis used life cycle cost, global warming potential, net energy yield and the potential for non-renewable resource depletion. The method used an aggregating function known to combine relative weightings of each criterion against the impacts of each fuel type. The study explored the impact of changing the relative weightings of each criterion.

Terrados et al. [22] used a multi-criteria analysis along with a SWOT analysis method to contribute to a report on regional development in Spain. Large biomass resources were identified as one of the major strengths for the region when looking to meet criteria regarding domestic provision of renewable energy.

Cherni et al. [23] presented a multi-criteria decision support system called SURE DSS (SUstainable Rural Energy decision support system) to select between eight different energy supply technologies. Using this method the technology options are scored against the categories of Physical, Financial, Human, Social and Natural impact. SURE DSS allows decision makers to examine the impact of installing different energy options on the livelihoods of local communities. The presented case study is set in a rural Columbian community.

Madlener et al. [24] used PROMETHEE to compare five different scenarios which assumed different proportions of electricity and heat produced by various mixtures of renewable technologies. One scenario was described as "Extensive use of Biomass". A mixture of 
qualitative and quantitative criteria is used to define the preferable scenario with expert opinion used to give each scenario a final score.

Afgan and Carvalho [25] used a multi criteria method based on a measuring parameter described as a general index of sustainability. The general index method requires the formation of an aggregate function using the weighting of different indicators. This method was used to evaluate the sustainability of different renewable energy technologies when used together, for instance PV with Wind technologies. The evaluation uses an economic, environmental and a social indicator set to evaluate sustainability. The study compares five contrasting energy systems which are evaluated in seven different cases where different coefficients are given different weightings. The coefficients used are electricity cost, investment cost, $\mathrm{NO}_{\mathrm{x}}$ emissions, $\mathrm{CO}_{2}$ emissions, efficiency and electricity cost.

Buchholz et al. [26] reported on a comparative review of several decision support systems when applied to a case study in Uganda. The study had a focus on multi-stakeholders and their roles in the decision making process. The multi-criteria decision tools used were SuperDecisions, DecidelT, Decision Lab and NAIADE. The study aimed to make a decision which would result in the most sustainable choice being made and found large variation of results from the various tools used. However social criteria were, in this case, always identified as being decisive to the outcome of each process.

Karagiannidis and Perkoulidis [27] combined the ELECTRE III decision method with fuzzy set logic to select between several different anaerobic digestion (AD) technology choices. The criteria used for the selection were greenhouse gas (GHG) emissions, recovered energy per tonne, recovered material per tonne and operating cost per tonne of feedstock. The study was completed for a case study waste stream identified in Greece.

Mohamadabadi et al. [28] also used the PROMETHEE method but this time to make a selection for fuels to be used in vehicles. Non renewable fuels were considered along with biofuels, electric-hybrid and compressed gas. Different criteria were then weighted against either an environmental scenario where more emphasis is placed on environmental outputs, or a cost scenario. The authors found that biodiesel fuel followed only the hybrid electrical choice for the environmental scenario. This paper also included a sensitivity analysis allowing the authors to identify which criteria were most important for the output ranking.

McDowall and Eames [29] examined the hydrogen economy using a multi-criteria mapping approach to decide between six potential hydrogen energy systems for the UK. The method involves moving through a decision structure from discussion of possible visions for future hydrogen economy through a conversation regarding uncertainty and finally to determine weighted preference ranking of the various different visions. Several of the visions for a hydrogen future economy suggested by the participants of the research involved the use of biomass resources to produce hydrogen. The various visions were given weightings by industry experts and the results vary to a greater or lesser extent across participants.

Ridolfi et al. [30] in a similar field to [29] evaluated different methods for producing hydrogen using different feedstocks including wood chips. The processes were evaluated in terms of exergy, emergy and economic analysis with each method of evaluation recommending a different conversion route. 
Terrados et al. [31] too used the PROMETHEE method along with a Delphi method for evaluating policy for planning in a region of Spain. The study aim is to produce a recommendation for the policy measures which will result in the most sustainable development. Criteria used in the analysis were banded under environmental and socioeconomic themes. Expert opinion was included through the use of the Delphi method.

Evans et al. [32] compared three technology types using either dedicated or residual biomass to determine which combination of biomass and technology is considered most sustainable for electricity generation. The criteria used for sustainability were categorised as $\mathrm{CO}_{2}$, availability, limitations, land and water use and social impacts. The paper concludes that using hardy crops on marginal or unusable land performs best against the sustainability criteria defined. The use of fertiliser is also highlighted as having negative sustainability impacts.

Kaya and Kahraman [33] applied an integrated VIKOR (VIšekriterijumsko KOmpromisno Rangiranje)-AHP method to select between different renewable energy technologies for a region of Turkey, the study then uses the same method to select the best location for the chosen technology out of a choice of six different locations. This method deals with the uncertain and vague opinions of energy policy decision makers using the AHP part of the method and interviews with decision makers, whilst the VIKOR process which is supplemented with a fuzzy methodology is used to make the selections.

Browne et al. [34] assessed different scenarios as informed by policy on the residential heating and electricity consumption for a city region in Ireland. The NAIADE software was used to complete a multi-criteria decision analysis (MCDA) and a mixture of qualitative and quantitative criteria were used for the assessment. An ecological footprint analysis for the same scenarios was also presented to allow for a comparison. The two methods found the same scenario as most preferable but gave different rankings of the remaining scenarios leading the authors to recommend that several different decision tools should be used when deciding upon policy measures or incentives.

Theodorou et al. [35] also used multi-criteria decision making to make recommendations to policy makers with the aim of comparing three different decision methods, AHP, PROMETHEE and ELECTRE. Here policies for incentivising PV deployment in Cyprus were assessed against the criteria of maturity, initial investment cost, efficiency, potential and public acceptance. The paper concludes that the multi-stakeholder nature of the government department makes AHP too involved and that the ELECTRE method is preferable given its flexibility.

Oberschmidt et al. [36] also applied the PROMETHEE method for technology selection. In this study various alternatives for provision of heat and power in a municipality in Germany were compared. The findings report that when considered over the lifetime of the plant using a lifecycle analysis approach renewable technologies can compete with fossil fuel technologies for this application.

Jovanovic et al. [37] examined a district heating application in Serbia with regards to using a blend of technology choices including biomass with either solar or natural gas for hot water provision. The analysis focused on five technologies and compared against a complex set of sub-criteria in a multi-criteria analysis. The approach taken avoids allowing the definition of 'sustainability' to be determined by the analysts involved and rather uses a set of energy 
indicators. This has the advantage that the decision would be consistent across similar schemes regardless of the personnel involved in decision making.

Pokoo-Atkins et al. [38] investigated the conversion of fatty-acid wastes into biodiesel. A specialist piece of software called ASPEN plus was used to model the chemical processes involved. A safety index and a set of techno-economic criteria were used to compare different process paths. The results are found to be dependent on the inclusion of safety concerns rather than any other criteria.

\subsection{Optimization of problems with many alternatives}

Problems which select from many or infinite options are more orientated towards mathematical optimization techniques which seek to create some objective function which is then maximized (profit) or minimized (cost) accordingly. The objective function can be used to incorporate multiple objectives by incorporating a weighting of different criteria to the objective function equation or a relevant penalty for attributes to be minimized [39]. Linear programming techniques are frequently used in these models although usually in combination with some method to develop criteria weightings and compare for overall success.

Suganthi and Williams [40] looked at ways to determine the optimal blend of renewable energy provision considering differing end users in the context of 2020 India. The study identifies critical parameters from which policy should be formed, and then uses an optimization model to compare various different 2020 scenarios.

Ayoub et al. [41] used an evolutionary algorithm in the setting of Japan to identify the solution for a resource assessment of biomass. The created decision support system (DSS) also determines which sources should be sourced from and how much should be taken from each. The DSS combines optimization algorithms with geospatial information on the location of resources and includes information on supply chain length between raw material and the conversion stage. The system is able to optimise for either energy efficiency, total cost, $\mathrm{CO}_{2}$ emissions, or to maximise employed labour hours. The authors highlight that further research will look to simultaneously optimise these objectives in a single integrated DSS.

Bastin and Longden [42] also used Geospatial Information Systems (GIS) to model the location of biomass resources within a region. This study models waste arisings using data from the UK census and uses the results of that analysis to identify suitable locations for Energy from Waste (EfW) plants. The GIS system is also then used to allocate each domestic waste source (household level) to a particular waste treatment facility. The allocation is done by distance alone and a set of social, economic and environmental criteria taken from [43] are given weightings in the multi-criteria analysis which impacts on the selection of suitable locations.

Afgan and Carvalho [15] used indicators for environmental, economic and social impacts to deal with the sustainability evaluation of different combinations of renewable technologies including biomass. The method allows the most sustainable hybrid combination of technologies.

Beck et al. [44] used optimization methods to set a target for energy planners and policy makers by choosing a preferred pathway of biomass conversion. The optimization method used techno-economic, environmental and social criteria and looks at the behaviour of 
different agents within the network influencing the final energy mix. The method is tested in a South African case study.

Brown et al. [45] presented a technical paper where multi-objective methods are used to assess the trade-off between cost and efficiency of a $20 \mathrm{MW}$ thermal wood gasification process.

Gassner and Marechal in [46] and [47] used evolutionary multi-objective optimization methods coupled with models of energy and finance flows to model technical operation of production processes. [46] presents a method to optimize the production of biofuel while [47] looked at optimizing the production of biogas from lingocellusoic material.

Herran and Nakata [48] used four attributes, electricity cost, employment, land use and $\mathrm{CO}_{2}$ emissions to make a decision on the optimal system configuration to meet electricity demand in an off-grid rural location. A goal programming algorithm is used to select the most suitable technologies to be used in this context.

Huang et al. [49] presented a model to assist with the planning of a bioethanol supply chain. A mathematical model is presented which is able to consider spatial and temporal information on the supply chain whilst satisfying resource demand and technology constraints and minimizing supply cost. The model is applied to a case study in the USA and finds that through careful configuration of the supply chain costs can be significantly reduced.

Rentizelas et al. [50] presented a decision support system for a multi-biomass system. This is unusual as most studies consider only a single, or two fuel types. The paper aims to assist with decisions around the design of a district heating and cooling network to optimize financial yield within multi-criteria constraints including social and regulatory aspects. The model is tested in a Greek context.

Stanojevic et al. [51] examined the environmental impact of energy generation from a green accounting perspective. In this context this involves translating the environmental impacts of an energy provision scheme into a monetary penalty for the operator. This paper uses 44 criteria which should either be minimized or maximized to give the lowest environmental cost, 26 of the 44 criteria are financially focussed. The study finds that biofuel fired combined heat and power (CHP) plants are most favourable and that their advantage increases over fossil fuel equivalents when financial criteria are ignored.

Ren et al. [52] gave a recommendation for the optimal energy system that could be used in Japanese residential buildings. The study used a multi-criteria analysis combined with linear programming techniques to make the decision along with the application of PROMETHEE and AHP to select between options. The study also includes a sensitivity analysis using 10 different scenarios and is able to examine four assessment criteria. In a related study Ren et al. [53] used a similar linear programming model to help with the design and evaluation of a biomass combined cooling, heat and power (CCHP) system. The model is able to optimize for the capacity of plant that will be required depending on demand side characteristics of the heat load. This model is tested in a Japanese building as a case study.

Vera et al. [54] solved the problem of where to locate a conversion facility using a binary honey bee foraging method. This determines the optimal location, where the supply area should be and the size of the plant to give the maximum profitability. The study also compared with genetic algorithm and particle swarm optimization approaches. 


\subsection{Predictive models}

The category of predictive models covers those studies which aim to model future scenarios of a given system. A predictive model will simulate the future based on the various factors of interest being modelled. For instance future events such as economic growth and energy demand may be simulated in order to calculate $\mathrm{CO}_{2}$ emissions, cost or other criteria given a certain energy technology blend.

Rozakis et al. [55] developed a multi-criteria model to assist the French government in making choices around the best policy for the French biofuel industry. A multi-level mixed integer linear programme is used to model the 450 participating arable farms. The model is able to predict the impact of different policies on the cost of biofuels. In a following short communication Sourie and Rozakis [56] reported on a model that allows micro-economic analysis of the biofuel industry using a multiple supply chains or sources. The approach is described as environmental economics and contains several criteria. Multi-criteria analysis is discussed for the approach which is described as environmental economics. This short communication is aimed at informing policy makers on the use of tax as an incentive for biofuel development.

Diakoulaki and Karangelis [57] examined many policies the Greek government could support to alter energy provision mix in the country. A set of scenarios are assessed in a multicriteria analysis against social, environmental and economic criteria. Each scenario specifies the blend of new and future total energy mix and makes suggestions as to the impact of supporting different technologies.

Briceno-Elizondo et al. [58] used a multi-criteria analysis model to simulate the Boreal Forrest over 100 years. This study uses stochastic input data and a stochastic treatment of alternatives to produce a measure of utility as defined by a previous model. A Monte-Carlo analysis is used to evaluate eight different Forrest treatment programmes against the objectives leading to utility, including Timber production, $\mathrm{CO}_{2}$ and biodiversity.

Mander et al. [59] reported on part 1 of the Tyndall decarbonisation scenario project and outlines various pathways for the UK to realise a 60\% reduction on 1990 greenhouse gas (GHG) levels by 2050. This paper gives a description of the methodology which will be used.

Anderson et al. [60] reported on part 2 of the same scenario modelling exercise by the Tyndall centre. This paper applies multi-criteria analysis to examine the impact of several different demand scenarios. The criteria used cover economic, social and environmental issues and the study finds that the higher demand scenarios have a greater negative impact on climate change.

\subsection{Qualitative methods}

This category of problems covers those papers which apply qualitative data collection methods to investigate and solve challenges around bioenergy. These methods are well suited to the multi-criteria approach this review examines as it allows for a depth and breadth of opinions to be captured. Several studies use qualitative methods to collect requirements or criteria before converting these to weightings which can be used in combination with the methods described above.

Shackley and McLachlan [61] looked at the North West of England using a multi-criteria assessment approach to collect views from stakeholders regarding a set of possible 
scenarios for future energy supply. The paper reports on the criteria identified by the stakeholders who were interviewed. The nine identified criteria were then grouped under the wider headings of environment, socially focused and business focused criteria.

Elghali et al. [62] took a slightly different approach to many other researchers in the field by moving away from assuming a single decision maker analysis and absolute objectivity with common scales and typically heavy data requirements. Instead a paradigm from Rosenhead and Mingers [63] is used which works towards seeking alternative solutions that are acceptable without demonstrating trade-offs and accepting that uncertainty will exist. This approach seeks a solution rather than an optimal and the Elghali et al. [62] study used the approach to model a life-cycle perspective of the supply chain of willow for energy. The study concludes that the created framework can be used as guidance to development of supply chains recognising social and environmental impacts as well as socio-economic barriers to development.

Buchholz et al. [10] examined how a DSS could be used to decide on the most suitable technology to satisfy sustainability criteria as determined by the stakeholders in the system. The authors discuss combining a multi-criteria analysis with systems thinking to provide the basis of a holistic decision tool. The study used results from stakeholder workshops to feed into an optimization DSS, allowing stakeholders to partly define their own definition of sustainability. The proposed DSS is intended to assist at the planning stage helping to select locations and technologies to best encourage sustainable development.

Upham et al. [64] looked at policy issues around biofuel use in a UK context at a regional level. The study collects the opinions of key stakeholders within the bioenergy industry and government as well as members of the public. The findings show that overall stakeholders preferred the option of combined heat and power (CHP) plants run on biofuel due to higher overall efficiency and perceived improvement in local employment.

Jablonski et al. [65] treated the qualitative assessment of market segments as a multicriteria analysis. The study examines the interactions between market segments through a qualitative score code. The paper proposes a framework involving dividing the heat market into segments based on fuel supply options, identifying key factors affecting the uptake of bioenergy for each segment, classifying those factors to identify barriers and finally identifying those which can be overcome. The results show a massive variation in market potential but that the most suitable heat market segment would be the residential segment.

Atwell et al. [66] presented the outcomes of a workshop held with key policy makers on the agricultural sector of the USA. The workshop aimed to discuss how agriculture and governing policy can be used to adapt to the rapid changes taking place due to increased energy crop growth. The aim of policy in this area is to meet the multi-objective social needs of private land owners in the face of this rapid reorganisation.

\subsection{Others}

The below papers appear in the literature search outlined in the method section 2 but do not directly apply the methods referred to in Table 2 . They therefore appear here in an others section.

Thornley [67] presented a detailed discussion on the use of biomass for power generation in the UK. The paper divides the 'benefits'; and 'consequences' of using biomass for electricity 
generation into environmental, social and economic categories. The study also discusses how different policies and incentive mechanisms can sit within the bioenergy industry.

Ghilardi et al. [68] used a geospatial information system to identify the locations of supply and demand of wood fuel in Mexico for residential use. The paper identifies hot spots of supply and shortage around the country. In a follow up paper Ghilardi et al. [69] identified locations for fuelwood use and availability based on a set of six indicators.

Raven et al. [70] mentioned multi-criteria analysis as a suitable method for conflict resolution in established projects where conflict already exists. The paper presents a slightly modified method for avoidance of conflict at the planning phase of an energy project. In this study conflict is discussed in terms of social acceptance by the general and wider public.

Münster and Lund [71] selected a suitable energy from waste (EfW) technology for biogas and biofuel production including gasification technologies. The paper uses a so called energy system analysis which allows a direct comparison between technologies based on the focus of the decision maker. The focus could be $\mathrm{CO}_{2}$, sustainability metrics, cost or efficiency amongst others as defined by the decision maker. The authors propose that the outputs from this method would be suitable for use in other decision tools such as cost-benefit or MCDA.

\section{Which methods are most frequently applied}

Table 4 shows the category of method most frequently applied to bioenergy problems was found to be optimization methods with $71.9 \%$ of all the reviewed papers using some form of optimization process. This is perhaps to be expected as the multi-criteria decision making techniques sit most comfortably within the decision sciences discipline. These papers were split fairly evenly between those that used algorithms to select from many or infinite options and those that selected from a limited number of options.

7 papers used qualitative techniques to gather and analyse primary information and these studies were able to focus on identifying success criteria and collect detailed opinions of key stakeholders in bioenergy systems.

6 papers used simulation or predictive models to draw conclusions on the future pattern of renewable implementation or energy use. This includes two papers by the Tyndall Centre on future scenario development for climate change and renewable energy technologies in the UK.

Table 4: Methods used

\begin{tabular}{|c|c|c|c|}
\hline Method Category & $\begin{array}{l}\text { Number of } \\
\text { papers }\end{array}$ & $\begin{array}{l}\text { Percentage } \\
\text { of papers } \\
\text { collected }\end{array}$ & References \\
\hline $\begin{array}{c}\text { Optimization of problems with few } \\
\text { alternatives }\end{array}$ & 25 & $43.9 \%$ & {$[14-38]$} \\
\hline Optimization via algorithm & 16 & $28.1 \%$ & $\begin{array}{c}{[41,42,44-} \\
54,68,69, \\
72]\end{array}$ \\
\hline
\end{tabular}




\begin{tabular}{|c|c|c|c|}
\hline Qualitative/stakeholder interview & 7 & $12.3 \%$ & $\begin{array}{c}{[10,56,61,} \\
62,64-66]\end{array}$ \\
\hline Predictive models & 6 & $10.5 \%$ & $\begin{array}{c}{[40,55,57-} \\
60]\end{array}$ \\
\hline Others & 3 & $5.3 \%$ & {$[67,70,71]$} \\
\hline
\end{tabular}

Figure 1a and Figure 1b show the breakdown of which methods have been used for each application area. Optimization by algorithms has the greatest range of applications being used for 9 of the 11 possible categories, whilst technology selection is most popular problem addressed. The environmental issues category does not appear as no paper deals only with that topic. Environmental issues of course do appear in the literature however such studies have been categorised under sustainability as these studies also investigate economic and social issues.

Figure $1 \mathrm{~b}$ shows that the most common method used was optimization from few alternatives. This method was most frequently applied to the technology selection problem. Optimization using algorithms was the next most applied method with a higher proportion of these papers addressing operational issues.

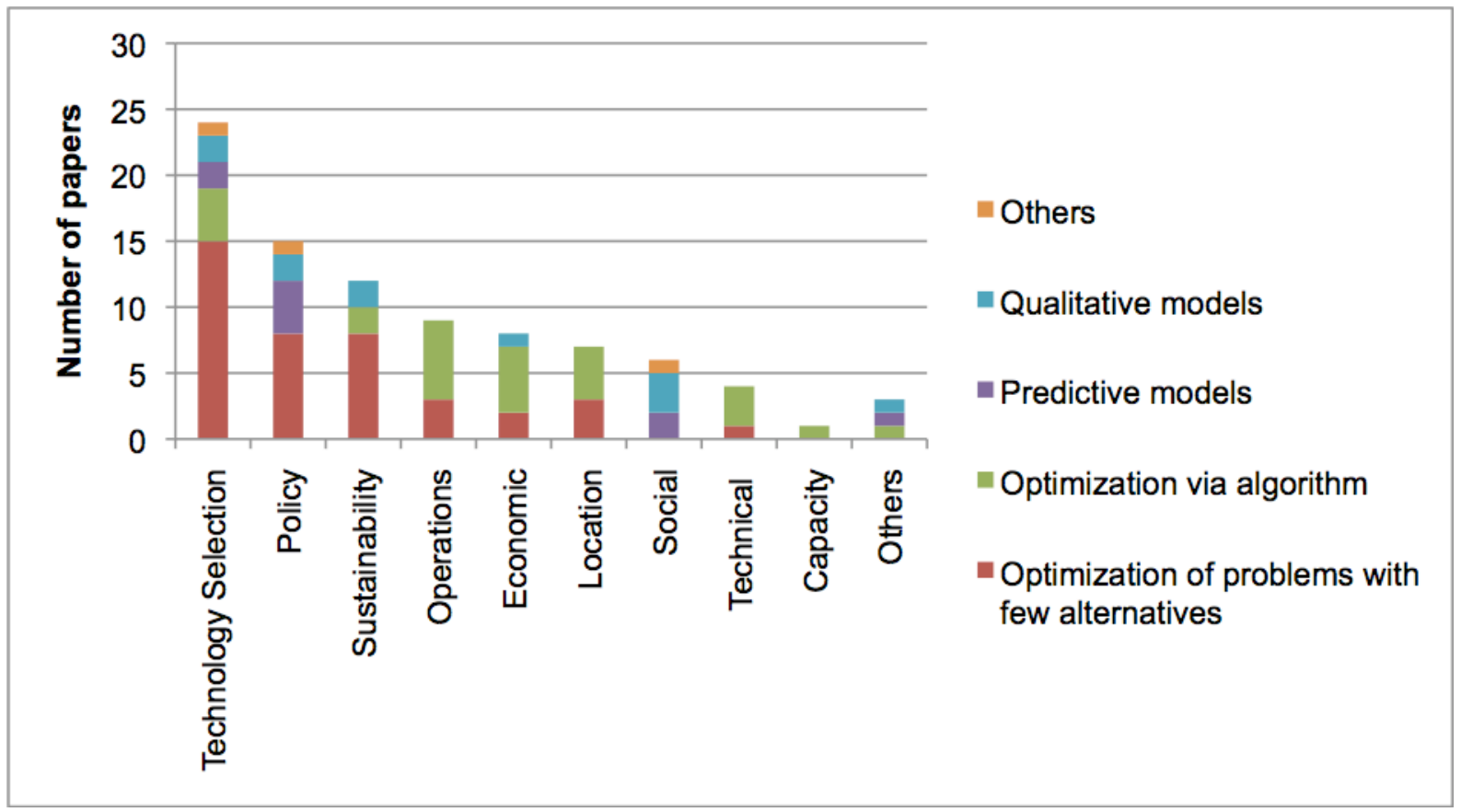

Figure 1a: Number of papers addressing a certain problem. 


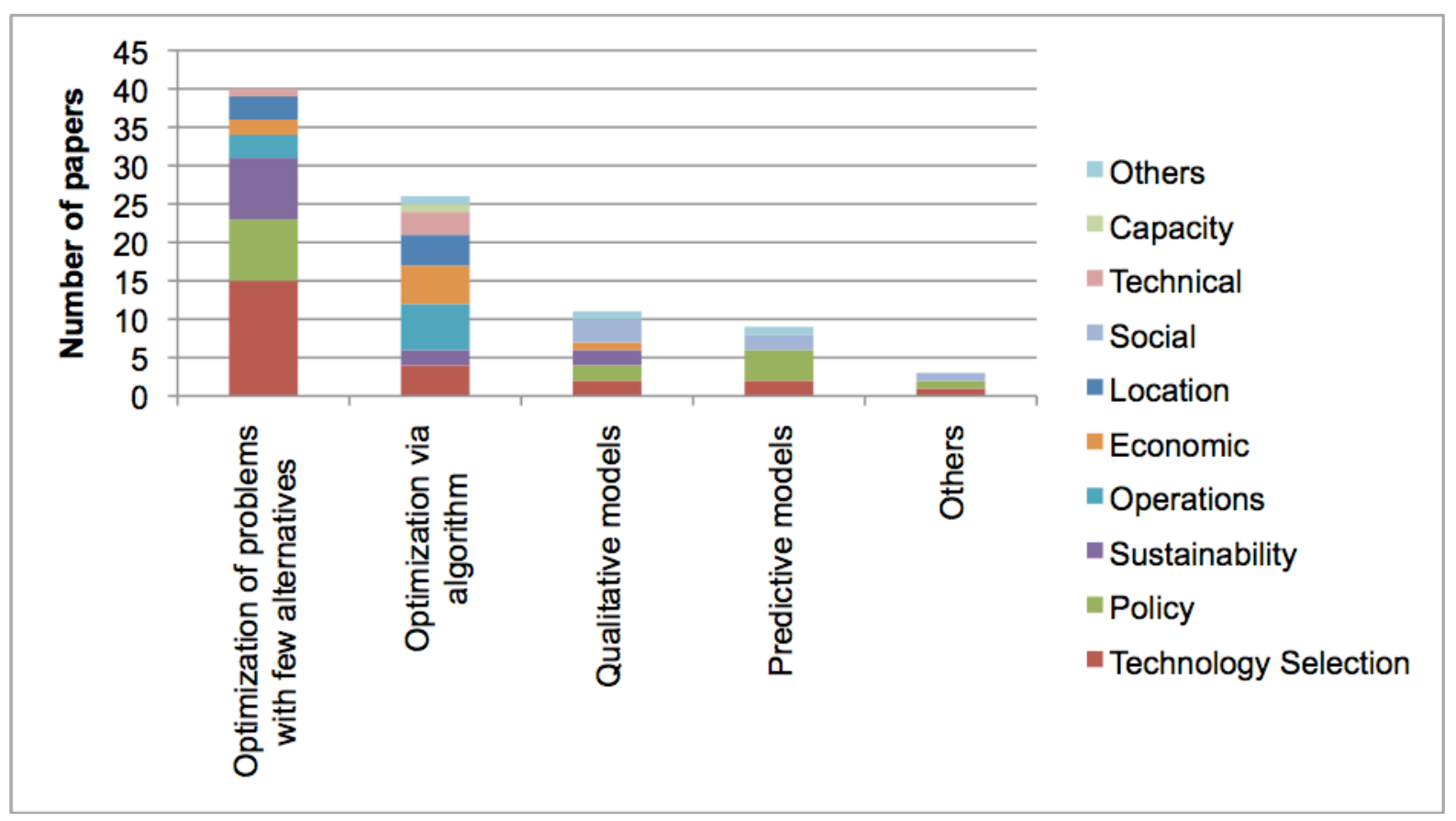

Figure 1b: Number of reviewed papers using a particular method.

\section{Which problems attract the most attention}

The most commonly studied problem in the reviewed literature was that of selecting which technology to use, or incentivise. 23 papers $(27.1 \%)$ addressed this problem by either comparing between renewable technologies (biomass vs. wind) or between renewable and non-renewable technologies or between types of technology or equipment within a technology type (different types of Anaerobic Digestion AD technology for instance).

The second most popular application regarded the problems around policy and legislation or legal issues with $17.6 \%$ of all reviewed papers. These papers either aimed to measure the impact of a certain policy or to make recommendations to policy makers, here again the most common combined problem was technology selection $[16,18,19]$. Three of the 15 studies were aimed at Greek policy makers and two at UK climate change policy.

Sustainability was the next most common topic for multi-criteria studies to address with $14.1 \%$ of the collected studies mentioning the measurement or consideration of either sustainability, or alternatively all three of economic, social and environmental issues. Because sustainability relies on the relationship and trade-off between these three pillars of sustainability the application of multi-criteria decision making and multi-criteria analysis would appear to be ideal. However difficulties will always arise in such approaches as, eventually, the MCDA requires some expert, user or knowledge database to specify how each aspect of each of these three pillars should be traded against any other. What is the monetary cost of each job created and sustained, what is the $\mathrm{CO}_{2}$ equivalent per year to that job? Several studies in this area take an approach which, rather than finding an absolute solution using some measurement of sustainability, aims to maximise sustainability as measured against a user definition of sustainability. There then appear to be two methods for examining sustainability of bioenergy systems; on one hand assuming that sustainability has global indicators which are true regardless of context $\left(\mathrm{CO}_{2}\right.$, economic sustainability), on the other hand trusting local actors to make accurate decisions regarding sustainability of a 
system from their own viewpoint. In the second case responsibility lies with the decision maker to fully understand a truly sustainable system. In the first case detail is lost at the local level with decisions made to fit a wider agenda than those stakeholders affected.

The most common combined application was technology selection combined with sustainability. For instance Afgan and Carvalho [15], Buchholz [26] and Jovanovic [37] all used the measurement of some sustainability impact or index to compare different technology alternatives against. This allows the most sustainable or least unsustainable technology to be selected.

Table 5: Summary of applications addressed

\begin{tabular}{|c|c|c|c|}
\hline Problem & $\begin{array}{l}\text { Number of } \\
\text { papers } \\
\text { addressing } \\
\text { problem }\end{array}$ & $\begin{array}{l}\text { Percentage of } \\
\text { papers } \\
\text { collected }\end{array}$ & References \\
\hline $\begin{array}{l}\text { Technology } \\
\text { Selection }\end{array}$ & 23 & $27.1 \%$ & $\begin{array}{l}{[10,14-21,23,25-} \\
28,32,36,37,40 \\
48,52,57,64,71]\end{array}$ \\
\hline Policy & 15 & $17.6 \%$ & $\begin{array}{c}{[16,18,19,22,} \\
30,31,34,35,55- \\
57,59,60,66,67]\end{array}$ \\
\hline Sustainability & 12 & $14.1 \%$ & $\begin{array}{c}{[10,15,21,24-26,} \\
29,32,33,37,48, \\
62]\end{array}$ \\
\hline Operations & 9 & $10.6 \%$ & $\begin{array}{c}{[29,30,41,49} \\
50,68,69,72,73]\end{array}$ \\
\hline Economic & 7 & $8.2 \%$ & $\begin{array}{c}{[27,45,49-51,56,} \\
72]\end{array}$ \\
\hline Social & 6 & $7.1 \%$ & $\begin{array}{c}{[40,55,61,64} \\
66,70]\end{array}$ \\
\hline Location & 5 & $5.9 \%$ & $\begin{array}{c}{[33,42,54,68,} \\
69]\end{array}$ \\
\hline Technical & 4 & $4.7 \%$ & {$[17,45-47]$} \\
\hline Capacity & 1 & $1.2 \%$ & [53] \\
\hline Environmental & 0 & $0.0 \%$ & $\mathrm{~N} / \mathrm{A}$ \\
\hline Others & 3 & $3.5 \%$ & {$[44,58,65]$} \\
\hline
\end{tabular}




\section{Other observations of the reviewed literature}

\subsection{National contexts of studies}

Many of the papers identified and reviewed have some national context against which the proposed method is assessed through case study, alternatively some research is national or regional by nature, recommendations on policy for instance are dependent on the national context of a particular country. From Figure $263.0 \%$ of the research that was applied in a regional or national context examined European countries. Table 6 shows that the UK and Greece are the most popular nations for studies although it should be noted that there are two Tyndall centre studies [59] \& [60] which both concern UK climate change policy whilst several of the Greek studies are a result of rapidly changing government legislation.

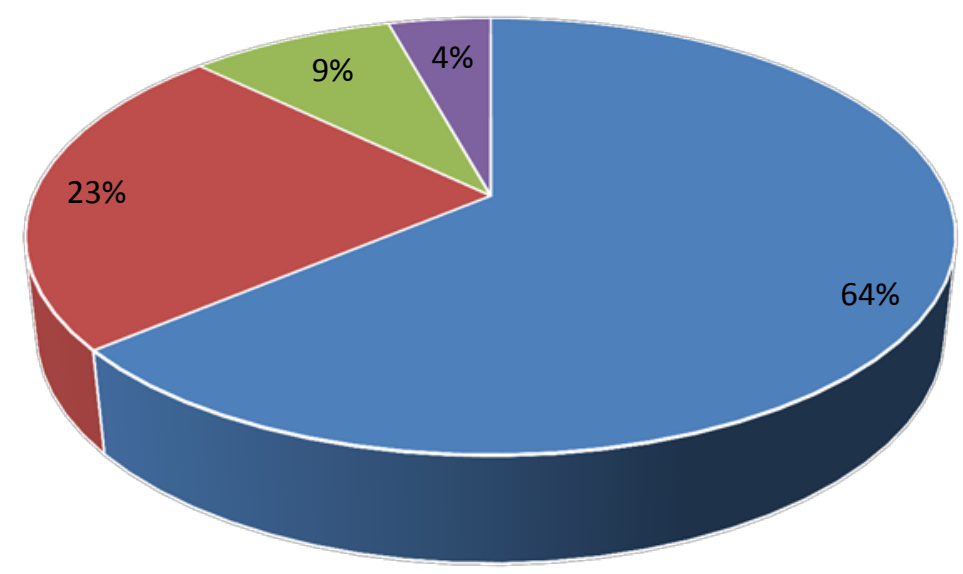

- European

- Americas

- Asian

- African

Figure 2: Research context addressed by the reviewed literature

Table 6: Number of reviewed papers using different national contexts

\begin{tabular}{|c|c|}
\hline National context & Number of studies \\
\hline UK & 9 \\
\hline Greece & 6 \\
\hline Japan, Spain & 3 \\
\hline $\begin{array}{c}\text { USA, France, Mexico, Turkey } \\
\text { Finland, India, Ireland, Sardinia, Serbia, South Africa, } \\
\text { Uganda }\end{array}$ \\
\hline
\end{tabular}




\subsection{Date of publications}

Figure 3 shows the number of papers in this review published in each year. The rate of publication increases in towards the end of the decade. This could reflect the increased interest in bioenergy in general by policy makers but also by developers and the power industry who are increasingly reactive to policy changes and incentives. The increase could also mark a movement away from the single criteria treatment of bioenergy problems and towards increased use of multi-criteria methods.

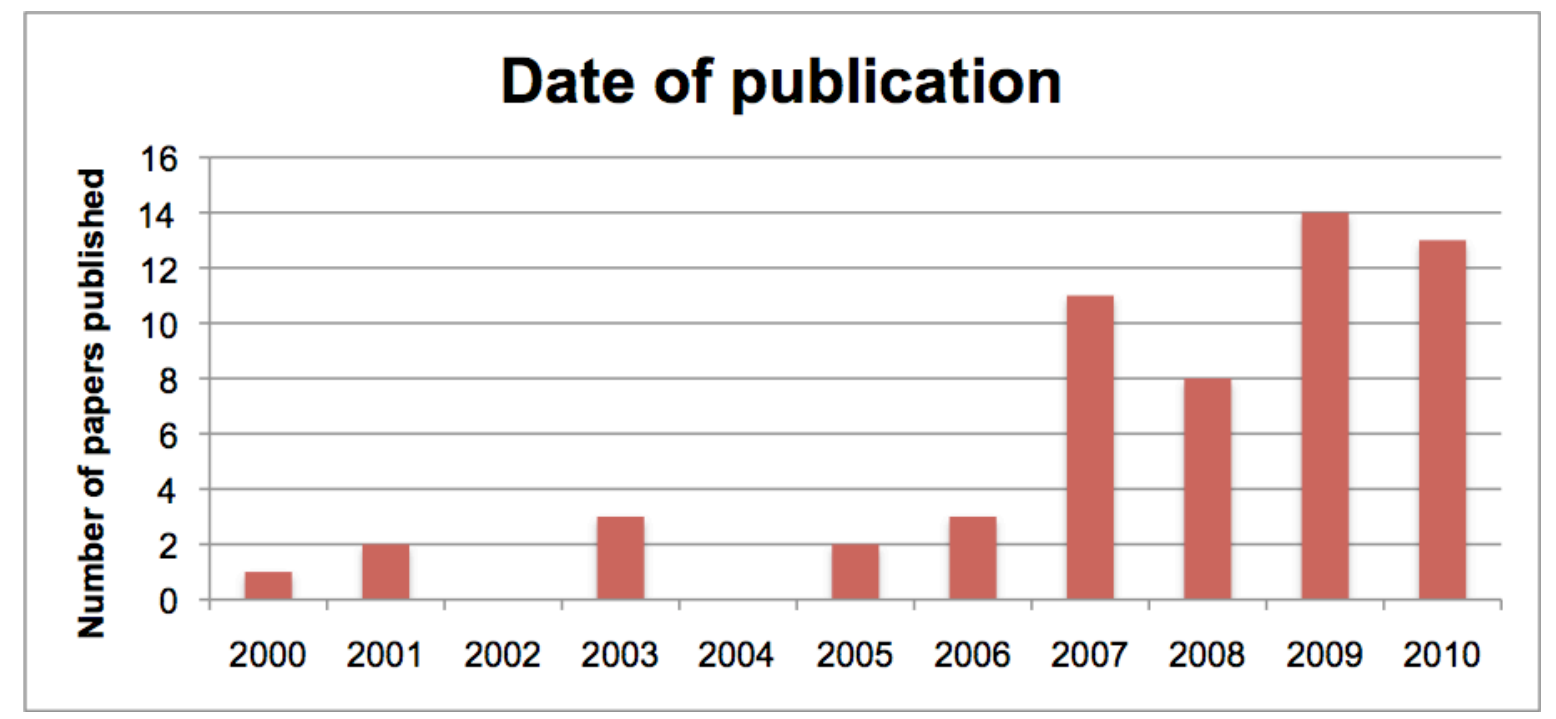

Figure 3: Publication date of the reviewed articles

\subsection{Publishing journals}

Figure 4 shows that a few journals have published several articles which appear in this review. The top five publishing journals are shown with the remaining 22 reviewed articles being published in a wide variety of other journals including Applied Energy, Land Use Policy, Computers Environment and Urban Systems and the Journal of Environmental Management.

The dominating journals reflect the interest in policy and technology selection identified in section 5 . 


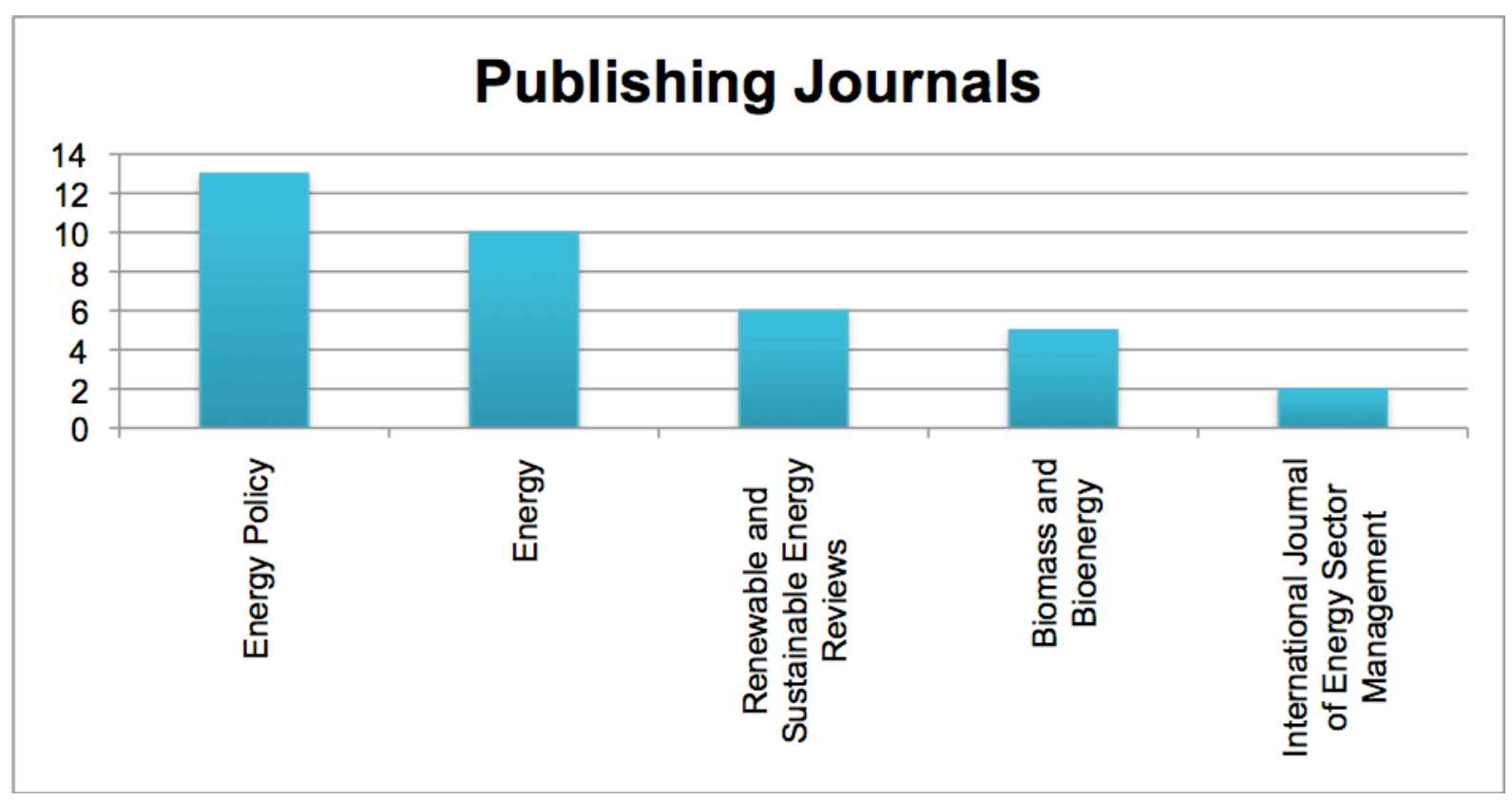

Figure 4: Journals publishing reviewed papers

\section{Findings and Future research}

Future work is required to fully address the requirements of the bioenergy industry through research, the contributions to date show a sound understanding of the impacts of decisions made regarding bioenergy scheme design and technology selection. Deployment of bioenergy in developed countries is expected to increase in the coming years as carbon reduction policies and targets begin to gather force. This industry growth will need to be well managed to ensure a sustainable industry is developed. Much of the reviewed literature appears to aim to influence and recommend to policy makers rather than address problems regarding location selection, supply of fuel or capacity selection using multicriteria methods. These operational and development issues are suitable for multi-criteria treatment and such methods could allow for more successful and efficient developments. Future work should engage clearly with current developments in the bioenergy industry to identify relevant problems during the implementation and design phases.

There are gaps in the breadth of literature regarding bioenergy systems. Of the categories used in this review the areas that have not received significant attention from the MCDA literature can be seen as being management or operational issues. These are determining the best plant capacity (1.2\%) managing and understanding the social impact of schemes (7.1\%), determining the best location for facilities (5.9\%), understanding and optimising the economics of schemes (8.2\%) and issues regarding the operation of the plant (10.6\%). These problems are addressed in other works but not using multi-criteria methods. Future research should aim to address these issues in a more complete way and create a basis for best practice in the bioenergy sector to be developed.

Regarding the management of operational and project planning issues around bioenergy schemes. Biomass supply chains have previously been identified as an obstacle to project finance and project success $[8,74,75]$ but have not received the same focus from multicriteria methods as other barriers to implementation such as technology choice or policy choice. These gaps could be addressed using existing multi-criteria methods from 
management science and principles of supply chain management. Supply chain issues have been studied using single criteria approaches for the bioenergy sector by several authors [76-79] and in several similar sectors [80-82] although only Ayoub et al. [41] applied a multicriteria approach, material supply chains are a key barrier for bioenergy deployment where multi-criteria methods could be applied. There are of course unique aspects of bioenergy supply chains which may not be suitable for traditional methods and may require novel treatment. In the operational category many decisions made in the design of fuel supply chains could be handled using MCDA methods including the sourcing, allocation and movement of biomass.

Regarding instances of opposition to bioenergy schemes from various stakeholders there are a diverse set of concerns and priorities $[70,83]$ including social, financial, environmental and health impacts. These types of problems could be addressed using MCDA methods such as goal programming with AHP to find a scheme that satisfies these concerns whilst ensuring the scheme design is feasible and economically viable.

This review has used search terms revolving around the bioenergy industry only. It is likely that methods exist in other industry sectors which could be suitable for addressing the problems being faced by the Bioenergy industry at present. For instance, the paper and wood pulp industries have a well-understood supply chain and the waste management literature may hold keys to making decisions about the treatment and movements of other types of biomass materials. These sections of the literature are not included in this review as indicated by the title and this could become a focus of future work as there is likely a wealth of potential cross over between application areas.

\section{Conclusions}

This paper has reviewed the relevant literature which uses MCDM techniques in the context of decision making around bioenergy schemes. This review identifies the rapidly expanding body of literature which contribute towards realising a best practice approach to the design and operation of bioenergy systems with 46 of the $57(80.7 \%)$ reviewed papers published between 2007 and 2010. However shortcomings remain in the breadth of literature which could be addressed through further MCDA research. Additionally many of the problems are not mature in the industry itself which has resulted in a case by case approach from academic research, each paper solving a particular problem without being able to interact with complimentary literature.

For bioenergy systems to properly be considered as multi-criteria problems it is necessary that all suitable aspects are examined from a multi-criteria perspective. This review identifies that works using MCDA in the bioenergy sector to date are not balanced against the potential applications of such methods nor do they currently fully address the problems faced by the bioenergy industry. Whilst MCDA methods may be easiest to apply to certain sub-problems of the bioenergy industry they may give more helpful support when applied in combination to obtain a truly optimal design from the viewpoint of all stakeholders. The intention of this paper is to systematically classify the existing literature which applied multi-criteria methods to the bioenergy industry and provide a direction for future research on supporting the design of existing and future bioenergy schemes. The main suggestions for future work are twofold. Firstly that a better understanding of optimal system configuration could be realised by integrating multi-criteria methods and applying such 
methods to more decisions in the development process; and secondly that there is scope to expand the use of MCDA methods in bioenergy allowing a better understanding of tradeoffs being made in decisions.

\section{Acknowledgements}

This research forms part of a project funded by the ESRC through the EREBUS (Engaging research for business transformation) cluster in the West Midlands region of the UK. Funding is awarded through a CASE studentship partly funded by a private company who have not been involved in the design or outcomes of this study.

\section{References}

[1] Edgard G. Assessing the sustainability of biofuels: A logic-based model. Energy. 2011;36(4):2089-96.

[2] Jebaraj S, Iniyan S. A review of energy models. Renewable and Sustainable Energy Reviews. 2006;10(4):281-311.

[3] Zhou P, Ang BW, Poh KL. Decision analysis in energy and environmental modeling: An update. Energy. 2006;31(14):2604-22.

[4] Kiranoudis CT, Voros NG, Maroulis ZB. Short-cut design of wind farms. Energy Policy. 2001;29(7):567-78.

[5] Wind resource assessment software. Refocus 2001. p. 34-5.

[6] Baños R, Manzano-Agugliaro F, Montoya FG, Gil C, Alcayde A, Gómez J. Optimization methods applied to renewable and sustainable energy: A review. Renewable and Sustainable Energy Reviews. 2011;15:1753-66.

[7] Wang J-j, Jing Y-y, Zhang C-f, Zhao J-h. Review on multi-criteria decision analysis aid in sustainable energy. Renewable and Sustainable Energy Reviews. 2009;13:2263-78.

[8] lakovou E, Karagiannidis A, Vlachos D, Toka A, Malamakis A. Waste biomass-to-energy supply chain management: A critical synthesis. Waste management (New York, NY). 2010.

[9] Turban E, Aronson JE, Liang T-P. Decision Support Systems and Intelligent Systems: Prentice Hall, 2004.

[10] Buchholz T, Volk T, Luzadis V. A participatory systems approach to modeling social, economic, and ecological components of bioenergy. Energy Policy. 2007;35:6084-94.

[11] Mareschal B. http://promethee-gaia.com/.

[12] Gass SI, Assad AA. An annotated timeline of operations research: an informal history. New York: Springer, 2005.

[13] Figueira J, Mousseau V, Roy B. Electre Mehtods. 3 ed. Boston: Springer Science + Business Media, Inc; 2005. p. 133-53.

[14] Beccali M. Decision-making in energy planning. Application of the Electre method at regional level for the diffusion of renewable energy technology. Renewable Energy. 2003;28:2063-87. 
[15] Afgan NH, Carvalho MG. Multi-criteria assessment of new and renewable energy power plants. Fuel and Energy Abstracts. 2003;44:102.

[16] Haralambopoulos DA, Polatidis $\mathrm{H}$. Renewable energy projects: structuring a multicriteria group decision-making framework. Renewable Energy. 2003;28:961-73.

[17] Khalil WA-S, Shanableh A, Rigby P, Kokot S. Selection of hydrothermal pre-treatment conditions of waste sludge destruction using multicriteria decision-making. Journal of Environmental Management. 2005;75:53-64.

[18] Ulutaş BH. Determination of the appropriate energy policy for Turkey. Energy. 2005;30:1146-61.

[19] Doukas H, Patlitzianas K, Psarras J. Supporting sustainable electricity technologies in Greece using MCDM. Resources Policy. 2006;31:129-36.

[20] Begic F, Afgan NH. Sustainability assessment tool for the decision making in selection of energy system--Bosnian case. Energy. 2007;32:1979-85.

[21] Zhou Z, Jiang H, Qin L. Life cycle sustainability assessment of fuels. Fuel. 2007;86:25663.

[22] Terrados J, Almonacid G, Hontoria L. Regional energy planning through SWOT analysis and strategic planning tools.: Impact on renewables development. Renewable and Sustainable Energy Reviews. 2007;11:1275-87.

[23] Cherni JA, Dyner I, Henao F, Jaramillo P, Smith R, Font RO. Energy supply for sustainable rural livelihoods. A multi-criteria decision-support system. Energy Policy. 2007;35:1493-504.

[24] Madlener R, Kowalski K, Stagl S. New ways for the integrated appraisal of national energy scenarios: The case of renewable energy use in Austria. Energy Policy. 2007;35:606074.

[25] Afgan NH, Carvalho MG. Sustainability assessment of a hybrid energy system. Energy Policy. 2008;36:2903-10.

[26] Buchholz T, Rametsteiner E, Volk T, Luzadis V. Multi Criteria Analysis for bioenergy systems assessments. Energy Policy. 2009;37:484-95.

[27] Karagiannidis A, Perkoulidis G. A multi-criteria ranking of different technologies for the anaerobic digestion for energy recovery of the organic fraction of municipal solid wastes. Bioresource Technology. 2009;100:2355-60.

[28] Mohamadabadi HS, Tichkowsky G, Kumar A. Development of a multi-criteria assessment model for ranking of renewable and non-renewable transportation fuel vehicles. Energy. 2009;34:112-25.

[29] McDowall W, Eames M. Towards a sustainable hydrogen economy: A multi-criteria sustainability appraisal of competing hydrogen futures. International Journal of Hydrogen Energy. 2007;32:4611-26.

[30] Ridolfi R, Sciubba E, Tiezzi E. A multi-criteria assessment of six energy conversion processes for H2 production. International Journal of Hydrogen Energy. 2009;34:5080-90.

[31] Terrados J, Almonacid G, Pérez-Higueras P. Proposal for a combined methodology for renewable energy planning. Application to a Spanish region. Renewable and Sustainable Energy Reviews. 2009;13:2022-30. 
[32] Evans A, Strezov V, Evans TJ. Sustainability considerations for electricity generation from biomass. Renewable and Sustainable Energy Reviews. 2010;14:1419-27.

[33] Kaya T, Kahraman C. Multicriteria renewable energy planning using an integrated fuzzy VIKOR \& AHP methodology: The case of Istanbul. Energy. 2010;35:2517-27.

[34] Browne D, O'Regan B, Moles R. Use of multi-criteria decision analysis to explore alternative domestic energy and electricity policy scenarios in an Irish city-region. Energy. 2010;35:518-28.

[35] Theodorou S, Florides G, Tassou S. The use of multiple criteria decision making methodologies for the promotion of RES through funding schemes in Cyprus, A review. Energy Policy. 2010:1-10.

[36] Oberschmidt J, Geldermann J, Ludwig J, Schmehl M. Modified PROMETHEE approach for assessing energy technologies. International Journal of Energy Sector Management. 2010;4:183-212.

[37] Jovanovic M, Turanjanin V, Bakic V, Pezo M, Vucicevic B. Sustainability estimation of energy system options that use gas and renewable resources for domestic hot water production. Energy. 2010.

[38] Pokoo-Aikins G, Heath A, Mentzer Ra, Sam Mannan M, Rogers WJ, El-Halwagi MM. A multi-criteria approach to screening alternatives for converting sewage sludge to biodiesel. Journal of Loss Prevention in the Process Industries. 2010;23:412-20.

[39] Derhy M-F. Linear Programming, Sensitivity Analysis and Related Topics: Pearson, 2010.

[40] Suganthi L, Williams A. Renewable energy in India - a modelling study for 2020-2021. Energy Policy. 2000;28:1095-109.

[41] Ayoub N, Elmoshi E, Seki H, Naka Y. Evolutionary algorithms approach for integrated bioenergy supply chains optimization. Energy Conversion and Management. 2009;50:294455.

[42] Bastin L, Longden DM. Comparing transport emissions and impacts for energy recovery from domestic waste (EfW): Centralised and distributed disposal options for two UK Counties. Computers, Environment and Urban Systems. 2009;33:492-503.

[43] Longden DM, Brammer J, Bastin L, Cooper N. Distributed or centralised energy-fromwaste policy? Implications of technology and scale at municipal level. Energy Policy. 2007;35:2622-34.

[44] Beck J, Kempener R, Cohen B, Petrie J. A complex systems approach to planning, optimization and decision making for energy networks. Energy Policy. 2008;36:2795-805.

[45] Brown D, Gassner M, Fuchino T, Marechal F. Thermo-economic analysis for the optimal conceptual design of biomass gasification energy conversion systems. Applied Thermal Engineering. 2009;29:2137-52.

[46] Gassner M, Marechal F. Methodology for the optimal thermo-economic, multiobjective design of thermochemical fuel production from biomass. Computers \& Chemical Engineering. 2009;33:769-81.

[47] Gassner M, Marechal F. Thermo-economic optimisation of the integration of electrolysis in synthetic natural gas production from wood. Energy. 2008;33:189-98. 
[48] Herran DS, Nakata T. Renewable technologies for rural electrification in Colombia: a multiple objective approach. International Journal of Energy Sector Management. 2008;2:139-54.

[49] Huang Y, Chen C-W, Fan Y. Multistage optimization of the supply chains of biofuels. Transportation Research Part E: Logistics and Transportation Review. 2010;46:820-30.

[50] Rentizelas AA, Tatsiopoulos IP, Tolis A. An optimization model for multi-biomass trigeneration energy supply. Biomass and Bioenergy. 2009;33:223-33.

[51] Stanojevic M, Vranes S, Gokal I. Green accounting for greener energy. Renewable and Sustainable Energy Reviews. 2010;14:2473-91.

[52] Ren H, Gao WJ, Zhou WS, Nakagami KDA. Multi-criteria evaluation for the optimal adoption of distributed residential energy systems in Japan. Energy Policy. 2009;37:5484-93.

[53] Ren H, Zhou W, Nakagami Ki, Gao W. Integrated design and evaluation of biomass energy system taking into consideration demand side characteristics. Energy. 2010;35:221022.

[54] Vera D, Carabias J, Jurado F, Ruiz-Reyes N. A Honey Bee Foraging approach for optimal location of a biomass power plant. Applied Energy. 2010;87:2119-27.

[55] Rozakis S, Sourie JC, Vanderpooten D. Integrated micro-economic modelling and multicriteria methodology to support public decision-making: the case of liquid bio-fuels in France. Biomass and Bioenergy. 2001;20:385-98.

[56] Sourie JC, Rozakis S. Bio-fuel production system in France : an Economic Analysis. Europe. 2001;20:483- 9.

[57] Diakoulaki D, Karangelis F. Multi-criteria decision analysis and cost-benefit analysis of alternative scenarios for the power generation sector in Greece. Renewable and Sustainable Energy Reviews. 2007;11:716-27.

[58] Briceno-elizondo E, Jager D, Lexer M, Garciagonzalo J, Peltola H, Kellomaki S. Multicriteria evaluation of multi-purpose stand treatment programmes for Finnish boreal forests under changing climate. Ecological Indicators. 2008;8:26-45.

[59] Mander SL, Bows A, Anderson KL, Shackley S, Agnolucci P, Ekins P. The Tyndall decarbonisation scenarios-Part I: Development of a backcasting methodology with stakeholder participation. Energy Policy. 2008;36:3754-63.

[60] Anderson KL, Mander SL, Bows A, Shackley S, Agnolucci P, Ekins P. The Tyndall decarbonisation scenarios-Part II: Scenarios for a 60\% CO2 reduction in the UK. Energy Policy. 2008;36:3764-73.

[61] Shackley S, McLachlan C. Trade-offs in assessing different energy futures: a regional multi-criteria assessment of the role of carbon dioxide capture and storage. Environmental Science \& Policy. 2006;9:376-91.

[62] Elghali L, Clift R, Sinclair P, Panoutsou C, Bauen A. Developing a sustainability framework for the assessment of bioenergy systems. Energy Policy. 2007;35:6075-83.

[63] Rosenhead J, Mingers J. Rational Analysis for a Problematic World Revisited: Problem Structuring Methods for Complexity, Uncertainty and Conflict Wiley, 2001. 
[64] Upham P, Shackley S, Waterman H. Public and stakeholder perceptions of 2030 bioenergy scenarios for the Yorkshire and Humber region. Energy. 2007;35:4403-12.

[65] Jablonski S, Pantaleo A, Bauen A, Pearson P, Panoutsou C, Slade RD. The potential demand for bioenergy in residential heating applications (bio-heat) in the UK based on a market segment analysis. Biomass and Bioenergy. 2008;32:635-53.

[66] Atwell RC, Schulte LA, Westphal LM. How to build multifunctional agricultural landscapes in the U.S. Corn Belt: Add perennials and partnerships. Land Use Policy. 2010;27:1082-90.

[67] Thornley P. Increasing biomass based power generation in the UK. Energy Policy. 2006;34:2087-99.

[68] Ghilardi A, Guerrero G, Masera O. Spatial analysis of residential fuelwood supply and demand patterns in Mexico using the WISDOM approach. Biomass and Bioenergy. 2007;31:475-91.

[69] Ghilardi A, Guerrero G, Masera O. A GIS-based methodology for highlighting fuelwood supply/demand imbalances at the local level: A case study for Central Mexico. Biomass and Bioenergy. 2009;33:957-72.

[70] Raven RPJM, Mourik RM, Feenstra CFJ, Heiskanen E. Modulating societal acceptance in new energy projects : Towards a toolkit methodology for project managers. Energy. 2009;34:564-74.

[71] Münster M, Lund HDODOljw. Comparing Waste-to-Energy technologies by applying energy system analysis. Waste Management. 2010;30:1251-63.

[72] Rentizelas AA, Tolis AJ, Tatsiopoulos IP. Logistics issues of biomass: The storage problem and the multi-biomass supply chain. Renewable and Sustainable Energy Reviews. 2009;13:887-94.

[73] Pokoo-Aikins G, Heath A, Mentzer RA, Mannan MS, Rogers WJ, El-Halwagi MM. A multicriteria approach to screening alternatives for converting sewage sludge to biodiesel. Journal of Loss Prevention in the Process Industries. 2010;23:412-20.

[74] Decc. Progress report on implementation of the government response to the biomass task force report. 2009.

[75] McCormick K, Kaberger T. Key barriers for bioenergy in Europe: Economic conditions, know-how and institutional capacity, and supply chain co-ordination. Biomass Bioenerg. 2007;31(7):443-52.

[76] Alex Marvin W, Schmidt LD, Benjaafar S, Tiffany DG, Daoutidis P. Economic Optimization of a Lignocellulosic Biomass-to-Ethanol Supply Chain. Chemical Engineering Science. 2012;67(1):68-79.

[77] Dunnett A, Adjiman C, Shah N. Biomass to Heat Supply Chains: Applications of Process Optimization. Process Safety and Environmental Protection. 2007;85(5):419-29.

[78] Gold S, Seuring S. Supply chain and logistics issues of bio-energy production. Journal of Cleaner Production. 2011;19(1):32-42.

[79] Tahvanainen T, Anttila P. Supply chain cost analysis of long-distance transportation of energy wood in Finland. Biomass and Bioenergy. 2011;35(8):3360-75. 
[80] Carlsson D, Rönnqvist M. Supply chain management in forestry-case studies at Södra Cell AB. European Journal of Operational Research. 2005;163(3):589-616.

[81] Mirzapour Al-e-hashem SMJ, Malekly $\mathrm{H}$, Aryanezhad MB. A multi-objective robust optimization model for multi-product multi-site aggregate production planning in a supply chain under uncertainty. International Journal of Production Economics. 2011;134(1):28-42.

[82] Ouhimmou M, D'Amours S, Beauregard R, Ait-Kadi D, Chauhan SS. Furniture supply chain tactical planning optimization using a time decomposition approach. European Journal of Operational Research. 2008;189(3):952-70.

[83] Upham P, Shackley S. Local public opinion of a proposed 21.5MW(e) biomass gasifier in Devon: Questionnaire survey results. Biomass and Bioenergy. 2007;31(6):433-41. 


\section{University Library}

\section{- M M I E R R A A gateway to Melbourne's research publications}

Minerva Access is the Institutional Repository of The University of Melbourne

Author/s:

Scott, JA;Ho, W;Dey, PK

Title:

A review of multi-criteria decision-making methods for bioenergy systems

Date:

2012

Citation:

Scott, J. A., Ho, W. \& Dey, P. K. (2012). A review of multi-criteria decision-making methods for bioenergy systems. Energy, 42 (1), pp.146-156. https://doi.org/10.1016/ j.energy.2012.03.074.

Persistent Link:

http://hdl.handle.net/11343/118658 